\title{
THE EFFECT OF HOSPITAL-PHYSICIAN INTEGRATION ON HEALTH INFORMATION TECHNOLOGY ADOPTION ${ }^{\dagger}$
}

\author{
ERIC LAMMERS* \\ Mathematica Policy Research and University of Michigan, Ann Arbor, MI, USA
}

\begin{abstract}
The US federal government has recently made a substantial investment to enhance the US health information technology (IT) infrastructure. Previous literature on the impact of IT on firm performance across multiple industries has emphasized the importance of a process of co-invention whereby organizations develop complementary practices to achieve greater benefit from their IT investments. In health care, employment of physicians by hospitals can confer greater administrative control to hospitals over physicians' actions and resources and thus enable the implementation of new technology and initiatives aimed at maximizing benefit from use of the technology. In this study, I tested for the relationship between hospital employment of physicians and hospitals' propensity to use health IT. I used state laws that prohibit hospital employment of physicians as an instrument to account for the endogenous relationship with hospital IT use. Hospital employment of physicians is associated with significant increases in the probability of hospital health IT use. Therefore, subsidization of health IT among hospitals not employing physicians may be less efficient. Furthermore, state laws prohibiting hospitals from employing physicians may inhibit adoption of health IT, thus working against policy initiatives aimed at promoting use of the technology. Copyright (C) 2012 John Wiley \& Sons, Ltd.
\end{abstract}

Received 6 December 2011; Revised 1 June 2012; Accepted 11 September 2012

KEY WORDS: hospitals; physicians; vertical integration; health information technology; transaction cost economics

\section{INTRODUCTION}

In 2009, the US Congress passed the American Recovery and Reinvestment Act, which appropriates funds to promote the adoption and use of health information technology (IT). The Medicare and Medicaid insurance programs are distributing these funds as rewards to providers for meeting various criteria for implementation and use of health IT with the goal of improving quality and cost-efficiency of care (Blumenthal and Tavenner, 2010). A prominent health IT application emphasized by the program is the computerized provider order entry (CPOE). CPOE helps providers to create and manage orders for patients' services and medication and has been promoted as an important component in improving patient safety (I.O.M, 2001). In theory, CPOE can reduce errors due to illegible handwriting, and with the aid of alerts, decision support, and detailed clinical information about a patient contained in an electronic medical record (EMR), it can help avoid adverse events from drugdrug interactions and known drug allergies. It can also enable faster delivery times to the pharmacy and may be less subject to errors caused by similar drug names and incorrect drug choices (Koppel et al., 2005).

This study contributes evidence regarding the relationship between vertical integration in healthcare and hospital use of clinical IT applications. It enhances our understanding of the organizational determinants of health IT adoption. Various cross-sectional and longitudinal studies have identified determinants of health IT adoption, including system affiliation, size, urban location, multihospital system membership, network effects,

*Correspondence to: Mathematica Policy Research, 220 E. Huron Street, Suite 300, Ann Arbor, MI 48104-1912, USA. E-mail: elammers@ mathematica-mpr.com

${ }^{\dagger}$ Supporting information may be found in the online version of this article. 
and not-for-profit ownership (Cutler et al., 2005; Kazley and Ozcan, 2007; McCullough, 2008; Miller and Tucker, 2009). Previous research on the relationship between IT and firm size and firm boundaries in other industries has found that increases in IT capital are associated with a decline in average firm size, consistent with case analyses and theoretical arguments, suggesting that IT lowers the costs of coordinating externally with suppliers, thus leading to less vertical integration (Brynjolfsson et al., 1994; Hitt, 1999). However, evidence from the introduction of on-board computers in the trucking industry indicates that this technology, serving as a monitoring device in that context, altered incentives related to ownership of trucks and thereby induced more vertical integration in that industry (Baker and Hubbard, 2004). Thus, findings in non-healthcare industries do not show a consistent relationship between IT and firm boundaries. In the healthcare context, McCullough and Snir (2010) found evidence of a positive relationship between exclusive hospital-physician affiliations and hospital use of IT applications that enhance monitoring of physician activities, including utilization review software and clinical data repositories.

Hospital-physician organizational arrangements come in various forms. The traditional medical staff model, by far the most common arrangement before the managed care era, involves only the granting of admitting privileges by a hospital to its physicians without direct financial ties between the two. During the managed care era, many hospitals entered into various arrangements with physicians, including at one extreme, direct employment of physicians. Although the era of tight managed care has passed, hospitals still face pressures from payers via negotiated payment rates, per diem or case rate payments, and Medicare's prospective payment system to control costs. Thus, coordination with physicians continues to be a concern for hospitals. Cuellar and Gertler (2006) provided a detailed discussion of other organizational arrangements between hospitals and physicians aside from employment.

In this study, I restrict the definition of hospital-physician integration to hospital employment of physicians and examine if this organizational form displays significantly different health IT adoption patterns relative to other looser hospital-physician affiliations. This restricted definition is warranted because employment is the most common form of integration between hospitals and physicians reported in the American Hospital Association (AHA) survey and has risen during the past decade while other forms have declined (Gaynor, 2011). This evidence is corroborated by recent independent research revealing that hospital employment of physicians, both specialists and primary care, is increasing nationwide (Casalino et al., 2008; O'Malley et al., 2011). Because the trend toward physician employment by hospitals coincides with increasing interest in stimulating health IT use, understanding any interactions between these two hospital strategies will inform both policies intended to influence health IT adoption and policies focused on hospital-physician relations, including antitrust regulation and initiatives fostering the development of Accountable Care Organizations.

\subsection{Conceptual model}

Because much benefit from health IT follows from reduced costs of communicating and managing patient information across multiple settings and over different episodes of care (Hillestad et al., 2005), providers' use of, or failure to use, the technology imposes an externality on other providers and the patients they serve (Miller and Tucker, 2009). Since the costs and benefits of investment in information systems do not accrue to a single provider, a public goods problem arises in which each agent has inadequate incentives to privately invest in the necessary technology.

Although many factors other than the coordination of information system investments contribute to hospital and physician decisions about whether to integrate, those hospitals that do employ their medical staff can more readily internalize the externality stemming from availability of patient data in electronic form. Without an exclusive hospital-physician affiliation, building necessary interfaces between inpatient and ambulatory information systems can be problematic because of the threat of regulatory actions under the federal Stark and antikickback laws prohibiting hospitals from offering financial incentives to independent physicians in return for referrals. Even with amendments to these laws in 2006 that were designed to facilitate hospital financing of IT implementation in physician practices, independent physicians must still contribute a substantial 
portion of the funds required for the technology (Grossman and Cohen, 2008). Hospitals that own physician practices face no such legal barriers to financing information systems that exchange patient data between settings of care, thus allowing them to capture greater benefit from these investments.

Furthermore, hospital employment of physicians confers advantages in the face of uncertainty, such as potential future changes in payment systems (e.g. movement by payers to impose greater risk-bearing or pay-for-performance on providers). Integration does this by centralizing control of hospital resources, including the medical staff and associated practice assets, under the authority of hospital administrators. Transaction cost economics, which I adopt as the framework for understanding the relative performance of physician employment versus looser arrangements, emphasizes advantages of authority compared with coordination among looser affiliates. These advantages flow from the ability of managers to reallocate resources in the face of uncertainty without the necessity of negotiating (Williamson, 1975; Menard, 2005). In the context of this study, we may understand hospital implementation of health IT as an adaptive response to the hospital's environment that requires cooperation from physicians. Integration between hospitals and physicians confers greater control to hospitals over physicians' actions and resources and thus enables a more beneficial implementation of the new technology.

I also draw on Jeffrey Harris' (1977) model of the internal organization of hospitals. Because of the uncertainty surrounding human disease processes, Harris highlights the importance to hospitals of rapid adaptation to "changing circumstances and new information" while determining the appropriate short-term allocation of resources. In theory, health IT can improve information management and communication in hospitals, thus enabling more efficient use of resources. These considerations contribute to hospital demand for health IT. However, as Harris points out, a tension exists between physicians, who serve as their patients' agents in procuring hospital resources, and hospital administrators, who must supply the necessary inputs for care without carrying too much excess capacity. This tension contributes to hospital administrators' desire for greater control over physician actions, thus leading to alignment strategies, such as directly employing physicians. Conditions for physician participation include compensation that meets or exceeds a minimum threshold determined by physician risk preferences and the profitability of owning an independent practice.

Furthermore, IT enhances the capability of hospitals to monitor the actions of affiliated physicians and structure incentives accordingly (McCullough and Snir, 2010). As noted by Masten (1988), certain legal requirements, such as employer liability for the actions of employees, enhance incentives to monitor employee activities more carefully relative to independent contractors' activities. When hospitals employ physicians, they assume malpractice liability that they would not otherwise have to bear for physicians (Cebul et al., 2008). This liability may motivate use of IT for monitoring purposes within tightly integrated health systems relative to hospitals more loosely affiliated with their medical staffs.

Alternatively, hospital use of health IT can substitute for direct employment of physicians by allowing hospitals to attract independent physicians through conveniences associated with health IT, such as ready access to inpatient information through physician internet portals or through a reputation effect as a sign of prestige. Because the relationship between physician employment and health IT may involve both complementarity and substitutability, empirical research can illuminate the relative magnitudes of these effects. In this study, I test for a relationship between hospital employment of physicians and the probability that hospitals adopt two prominent health IT applications-EMR and CPOE.

\section{DATA AND METHODS}

\subsection{Data sources}

The Health Information Management Systems Society (HIMSS) Analytics database for 2008 provides information on hospital use of health IT applications for more than 4800 nonfederal acute care hospitals in the USA-a near census of such hospitals. Included in the database are variables indicating hospital use of enterprise-wide EMR and CPOE. Respondents to this survey report if they have an operational system or not. The AHA annual 
survey for 2008 provides information on hospital characteristics, including employment of physicians, for more than 6000 hospitals, including 4678 nonfederal general hospitals. I merged the HIMSS Analytics database with the AHA data using various hospital identifiers common to both data sets, including the hospitals' Medicare provider numbers, names, and addresses. After merging these data sets, the sample consists of 4502 nonfederal general hospitals observed in 2008. The 2008 Area Resource File provides data on countylevel demographics.

For part of the analysis, I used data regarding state corporate practice of medicine (CPM) laws. The CPM doctrine, which has been defined primarily through case law interpretations of state medical practice acts, prohibits unlicensed entities (nonphysicians) from employing medical doctors (Kim, 2007). In some states, this doctrine has been extended to prohibit the employment of physicians by hospitals. Some states only prohibit for-profit hospitals. Previous research substantiates the premise that these laws present a binding constraint for many hospitals subject to them. A 1991 Department of Health and Human Services study involving a random sample survey of hospital administrators found that the laws impose "legal, recruitment or administrative costs," and "make it more difficult to staff medical services" (Yessian et al., 1991). A recent analysis of California's CPM doctrine notes that, despite availability of alternative integrated arrangements between hospitals and physicians, "the complexity and costs of such efforts may preclude smaller, financially weaker, and rural hospitals from pursuing them (Draper et al., 2009)."

A research assistant did comprehensive searches of state and federal statutes and case law and consulted state medical societies and previous CPM studies to identify states that apply the doctrine to hospital employment of physicians. Figure 1 shows states that were found to enforce CPM against hospital employment of physicians in two groups: (1) those restricting both not-for-profit and for-profit hospitals and (2) those restricting only for-profits. All other states were not found to have a CPM law that prohibits hospital employment of physicians. Within those states that apply the CPM doctrine to not-for-profit hospitals, there are exceptions for particular classes of hospitals (Draper et al., 2009). The exceptions to CPM in those states that apply the law to hospitals are described in an appendix. From these data, I constructed a hospital-level indicator for binding CPM restrictions against employing physicians. To the extent that exempt hospitals are identifiable with the AHA survey (e.g. because of nonprofit or government ownership or teaching status in some states), the indicator variable for CPM takes into account the various exceptions within those states that apply the restriction.

Table I provides summary statistics for the variables used in the estimations described. I report results and summary statistics only for the sample with nonmissing data. These summary statistics are also presented with

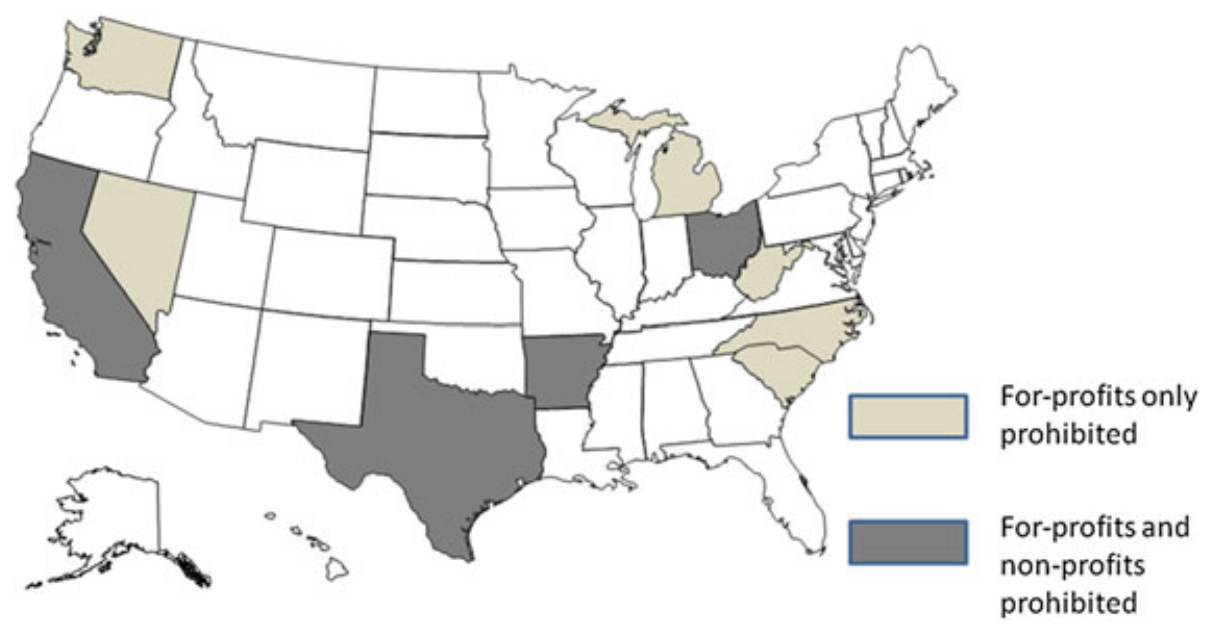

Figure 1. States that have a corporate practice of medicine statute or case law prohibiting some hospitals from employing physicians 
Table I. Descriptive statistics for general hospitals in 2008 stratified by state laws restricting the corporate practice of medicine

\begin{tabular}{|c|c|c|c|c|}
\hline & $\begin{array}{c}\text { All } \\
\text { hospitals } \\
(N=3493)\end{array}$ & $\begin{array}{l}\text { Bound by state restrictions } \\
\text { on physician employment } \\
\qquad(N=616)\end{array}$ & $\begin{array}{l}\text { Not bound by state restrictions } \\
\text { on physician employment } \\
\qquad(N=2877)\end{array}$ & \\
\hline Variable & Mean & Mean & Mean & $\begin{array}{c}P \text { value from } t \text {-test } \\
\text { of difference in } \\
\text { means }\end{array}$ \\
\hline \multicolumn{5}{|l|}{ Dependent variables } \\
\hline CPOE & 0.24 & 0.19 & 0.25 & 0.002 \\
\hline EMR & 0.48 & 0.37 & 0.51 & $<0.001$ \\
\hline \multicolumn{5}{|l|}{ Comparison technologies } \\
\hline Business intelligence & 0.27 & 0.32 & 0.26 & 0.003 \\
\hline Data warehousing & 0.28 & 0.30 & 0.28 & 0.34 \\
\hline Financial modeling & 0.29 & 0.30 & 0.28 & 0.49 \\
\hline \multicolumn{5}{|l|}{$\begin{array}{l}\text { Organizational arrangement } \\
\text { with physicians }\end{array}$} \\
\hline $\begin{array}{l}\text { Employs physicians } \\
\text { (integrated salary model) }\end{array}$ & 0.36 & 0.15 & 0.40 & $<0.001$ \\
\hline \multicolumn{5}{|l|}{ Hospital characteristics } \\
\hline $\begin{array}{l}\text { Member of the council of } \\
\text { teaching hospitals }\end{array}$ & 0.072 & 0.005 & 0.09 & $<0.001$ \\
\hline $\begin{array}{l}\text { Government owned } \\
\text { (nonfederal) }\end{array}$ & 0.24 & 0.23 & 0.25 & 0.35 \\
\hline Nonprofit ownership & 0.64 & 0.53 & 0.66 & $<0.001$ \\
\hline For profit ownership & 0.12 & 0.24 & 0.09 & $<0.001$ \\
\hline Total admissions & 8,154 & 7,424 & 8,310 & 0.0163 \\
\hline $\begin{array}{l}\text { Member of a multihospital } \\
\text { healthcare system }\end{array}$ & 0.55 & 0.61 & 0.53 & $<0.001$ \\
\hline Percent Medicare discharges & 0.49 & 0.48 & 0.50 & $<0.001$ \\
\hline Percent Medicaid discharges & 0.16 & 0.17 & 0.16 & 0.09 \\
\hline \multicolumn{5}{|l|}{$\begin{array}{l}\text { Geographic and market } \\
\text { characteristics }\end{array}$} \\
\hline Metropolitan CBSA & 0.55 & 0.66 & 0.52 & $<0.001$ \\
\hline $\begin{array}{l}\text { Herfindahl-Hirschman Index } \\
\text { by HRR for total admissions }\end{array}$ & 3,263 & 2,860 & 3,350 & $<0.001$ \\
\hline $\begin{array}{l}\text { Median household income in } \\
\text { county }\end{array}$ & $\$ 48,252$ & $\$ 48,842$ & $\$ 48,126$ & 0.22 \\
\hline $\begin{array}{l}\text { Medicare managed care } \\
\text { penetration in the county }\end{array}$ & 0.18 & 0.19 & 0.17 & 0.003 \\
\hline $\begin{array}{l}\text { Located in a state with } \\
\text { corporate practice of medicine } \\
\text { restrictions }\end{array}$ & 0.28 & 1 & 0.13 & $<0.001$ \\
\hline \multicolumn{5}{|l|}{ Other state regulations } \\
\hline $\begin{array}{l}\text { Electronic discovery laws } \\
\text { (ca. 2007) }\end{array}$ & 0.32 & 0.50 & 0.29 & $<0.001$ \\
\hline $\begin{array}{l}\text { Privacy protection laws } \\
\text { (ca. 2002) } \\
\text { Instrument }\end{array}$ & 0.49 & 0.77 & 0.43 & $<0.001$ \\
\hline $\begin{array}{l}\text { Bound by law prohibiting } \\
\text { hospital employment of } \\
\text { physicians }\end{array}$ & 0.18 & 1 & 0 & \\
\hline
\end{tabular}

HRR, hospital referral region

stratification according to whether the hospital is bound by corporate practice of medicine restrictions and $P$ values from $t$-tests of differences in means. In the case of for-profit status and teaching status, differences between hospitals bound by the law and those not bound follow obviously from differential application of the law between for-profits and nonprofits and academic versus nonacademic hospitals in some states. Because there are several significant differences in observed characteristics between hospitals bound by the law and 
those not bound by the law, in the regression analyses, I control for a rich set of observed hospital characteristics on the assumption the law is validly excluded as a predictor of health IT use conditional on the observed hospital characteristics.

In 2008, thirty-five percent of the sample reported having an employment arrangement with their physicians. As expected, a substantially larger proportion of hospitals that are not bound by CPM laws report employment of physicians. Although the laws technically prohibit integration as defined in this article, they imperfectly (but strongly) predict nonintegration due to some exempt hospitals that cannot be identified with the available data, possible variation in enforcement practices, and reporting error regarding integration in the survey. The problem of reporting error is mitigated by the instrumental variable strategy used in this study.

For comparison, I also examined hospital use of several administrative IT applications, including business intelligence software, financial modeling, and financial data warehousing. These computer-based applications are designed to provide performance data for business and financial measures to support management decision making. They were in use by proportions of hospitals similar to those using the clinical applications in this study. By ruling out a strong association between these applications and hospital-physician integration, I established further evidence that the effect of integration on health IT is due to a complementary relationship between physician employment and the technology as described in my conceptual model and not due to another mechanism.

Relevant hospital characteristics are included as control variables. In particular, membership in the council of teaching hospitals, for-profit, not-for-profit, and government ownership and the proportion of patients insured by government payers (Medicare and Medicaid) are included in the estimates. As a measure of the managed care environment faced by hospitals, the Medicare managed care penetration rate is also included. Linear splines for total admissions are included as a measure of hospital size. To improve the fit of the models, I tested for differences in the coefficients of spline segments and combined those that were not found to be significantly different from one another. This procedure resulted in two segments for total admissions in the CPOE estimation, four in the EMR estimation, and four in the comparison technology regressions. Competition among hospitals is measured using the Herfindahl-Hirschman Index (HHI) for which higher values indicate more concentrated markets. For this study, a market is a hospital referral region (HRR), defined by the Dartmouth Atlas as a regional market for tertiary care based around hospitals that provide major cardiovascular procedures and neurosurgery (Dartmouth Medical, 1998).

\subsection{Empirical model}

I estimated the probability that a hospital has a particular health IT application (EMR and in a separate regression, CPOE) cross sectionally as a function of hospital-physician integration using probit. However, because hospitals make decisions about health IT and physician employment with consideration for the same sets of circumstances, unobserved hospital characteristics can contribute to bias in estimating the relationship between these two variables. For example, higher costs of maintaining an independent physician practice in some markets may lead to substantially more hospital-based employment. Previous research using consulting reports, surveys, and case studies documents rising overhead costs in independent practice as contributing to more physicians accepting hospital employment in recent years (Burns and Muller, 2008). These costs of maintaining independent physician practices will be correlated with local costs of adopting health IT, such as labor costs for professionals needed to support use of the new technology. These costs, in turn, reduce hospital propensity to adopt health IT even while an employed physician staff reduces other organizational impediments to adoption. Thus, the correlation between unobserved physician practice costs and unobserved labor costs for IT will bias coefficient estimates toward zero in a single equation estimation of the relationship between hospital-physician integration and hospital propensity to use health IT.

To mitigate bias from the endogeneity of hospital-physician integration, I used information about whether hospitals are prohibited by state laws from directly employing physicians as an instrumental variable in a bivariate probit regression. Because these state laws have remained static during the period over which EMR 
and CPOE have diffused, I estimated a single period cross-sectional regression for 2008-the latest year for which data were available, and also the year during which there is the greatest variation in hospital use of the technology and hospital employment of physicians so far. Having substantial variation in these two hospital characteristics is, of course, necessary for estimating the relationship of interest.

The model is presented in the following equations:

$$
\begin{aligned}
T_{h}{ }^{*} & =\beta_{0}+\beta_{1} I_{h}+\boldsymbol{\beta}_{2} \text { HOSPITAL }_{h}+\boldsymbol{\beta}_{3} \text { MARKET }_{h}+\varepsilon_{T} \\
T_{h} & =1\left(T_{h}{ }^{*}>0\right) \\
I_{h}{ }^{*} & =\theta_{0}+\theta_{1} \text { RESTRICTIONS }_{h}+\boldsymbol{\theta}_{2} \text { HOSPITAL }_{h}+\boldsymbol{\theta}_{3} \text { MARKET }_{h}+\varepsilon_{I} \\
I_{h} & =1\left(I_{h}{ }^{*}>0\right)
\end{aligned}
$$

Hospital $h$ 's adoption of health IT $(T)$ is a function of an unobserved latent index variable $\left(T^{*}\right)$, which represents hospital $h$ 's propensity to adopt health IT. $T^{*}$ in turn is a linear function of integration with physicians (I) - a dichotomous variable - a vector of hospital characteristics (HOSPITAL) and a vector of hospital market characteristics (MARKET). Integration status is treated as endogenous, whereas all other hospital and market characteristics are regarded as exogenous. Integration status $(I)$ is modeled as a function of state laws prohibiting physician employment (RESTRICTIONS) as well as vectors of hospital characteristics (HOSPITAL) and hospital market characteristics (MARKET). This strategy produces consistent estimates of the coefficient on hospital employment of physicians in Equation (1) from which I calculate the incremental effect of hospital-physician integration on the probability of health IT adoption. The key identifying assumptions in terms of this model are that RESTRICTIONS affects integration, and only influences $T$ (with adjustment for other observed variables) through its effect on $I$ and is therefore uncorrelated with $\varepsilon_{T}$. The error terms in the two latent index functions, $\varepsilon_{T}$ and $\varepsilon_{I}$, are modeled as having a bivariate normal distribution. Because of the crucial role of state-level policies in the identification strategy, all regressions allow for correlation in the error components among hospitals in the same state.

\section{RESULTS}

Probit estimates of the effect of physician employment on hospital use of health IT yield insignificant positive results. Table II displays the average marginal effects from the probit estimates for EMR and CPOE. Significant predictors of health IT use include teaching status, total admissions, and metropolitan location. For-profit status has a significant negative relationship with both forms of health IT relative to private nonprofit hospitals, whereas government ownership has a significant negative relationship only for EMRs relative to private nonprofits. Median household income has a significant positive relationship with CPOE, but not with EMR systems.

Furthermore, I estimated the probability of health IT use as a function of integration status, other hospital characteristics, and market/county characteristics using recursive bivariate probit with state corporate practice of medicine laws as an instrument for hospital-physician integration. Bhattacharya et al. (2006) document evidence on the advantages of recursive bivariate probit relative to other instrumental variables (IV) strategies for estimating treatment effects when both outcome and treatment variables are dichotomous.

Table III reports average marginal effects from the estimate of the probability of hospital-physician integration (the first stage equation of the bivariate probit regression). Consistent with expectations, binding CPM laws produce a significant 24 percentage point decline in the probability of employing physicians. Other results from estimating the probability of hospital-physician integration indicate that for-profit hospitals are significantly less likely to employ physicians than nonprofits. Operating in a more concentrated market is 
Table II. Average marginal effects from naive probit estimation of CPOE and EMR use as a function of integration status in 2008

\begin{tabular}{|c|c|c|}
\hline & EMR & CPOE \\
\hline Variables & $\partial \Phi(T) / \partial X_{\mathrm{EMR}}$ & $\partial \Phi(T) / \partial X_{\mathrm{CPOE}}$ \\
\hline \multicolumn{3}{|l|}{ Endogenous variable } \\
\hline Integrated salary model & $0.014(0.020)$ & $0.014(0.019)$ \\
\hline \multicolumn{3}{|l|}{ Hospital characteristics } \\
\hline Member of the council of teaching hospitals & $0.123 * * *(0.045)$ & $0.122 * * *(0.035)$ \\
\hline For profit & $-0.325 * * *(0.047)$ & $-0.055^{* *}(0.028)$ \\
\hline Government owned (nonfederal) & $-0.060 * *(0.026)$ & $-0.005(0.023)$ \\
\hline Member of a healthcare system & $0.037 *(0.023)$ & $0.026(0.017)$ \\
\hline Percent Medicare discharges & $-0.052(0.090)$ & $-0.157 * *(0.065)$ \\
\hline Percent Medicaid discharges & $-0.08(0.14)$ & $-0.12(0.12)$ \\
\hline \multicolumn{3}{|l|}{ Total admissions (1000) splines } \\
\hline$<1.34$ & & $0.101 * * *(0.029)$ \\
\hline$>1.34$ & & $0.00397 * * *(0.00083)$ \\
\hline$<0.43$ & $0.36 *(0.20)$ & \\
\hline $0.43-2.23$ & $0.124 * * *(0.020)$ & \\
\hline $2.23-8.63$ & $0.0125 * * *(0.0049)$ & \\
\hline$>8.63$ & $0.0005(0.0015)$ & \\
\hline \multicolumn{3}{|l|}{ Geographic and market characteristics } \\
\hline Metropolitan or division CBSA & $0.044 *(0.024)$ & $0.071 * * *(0.017)$ \\
\hline Herfindahl Hirschman Index (rescaled by 1000) by HRR & $0.009(0.010)$ & $0.003(0.011)$ \\
\hline Median household income in county (in $\$ 10,000$ ) & $0.0085(0.011)$ & $0.0202 * *(0.0083)$ \\
\hline Medicare managed care penetration in county & $0.036(0.093)$ & $0.131 *(0.069)$ \\
\hline$N$ & 3493 & 3493 \\
\hline
\end{tabular}

Standard errors calculated by the delta method are reported in parentheses. Estimates allow for correlation in the error terms within states. HRR, hospital referral region.

*Statistically significant at the $10 \%$ level.

**Statistically significant at the $5 \%$ level.

$* * *$ Statistically significant at the $1 \%$ level.

associated with a higher probability of employing physicians. Among larger hospitals, total admissions are positively associated with the probability of integration.

Table IV reports average marginal effects on the probability of health IT use $(\partial \Phi(T) / \partial x)$ from the health IT bivariate probit regressions. Standard errors for the average marginal effect estimates from these regressions were calculated using the delta method. The average marginal effects indicate a significant positive relationship between physician employment and the use of both EMR and CPOE. Here, I found that integration is associated with a 24 percentage point increase in the probability of CPOE use and a thirty-nine percentage point increase in the probability of EMR use. Teaching status and metropolitan location remain significant positive predictors of both health IT applications. Total patient admissions, within some ranges, is significantly and positively associated with the probability of both forms of health IT. Although the marginal effect of for-profit status remains a significant negative predictor of the probability of EMR use, it is not statistically significant in the CPOE regression, contrary to the univariate probit results. It does, however, have a negative direct effect as with univariate probit. These results suggest that much of the negative effect of for-profit status on CPOE use comes indirectly through its negative effect on integration.

A test of the strength of the excluded instrument produces a chi-square test statistic of 24 , indicating a reasonably strong instrument (Table IV). The other requirement that an instrument must satisfy to be valid is an exclusion restriction - in this case, CPM laws should only influence the probability of health IT adoption through hospital-physician integration and not through any unobserved variable. Because the CPM laws predate the adoption of modern information systems and have remained static with respect to hospitals ever since, these laws (adjusted for observed hospital characteristics) are plausibly uncorrelated with EMR and CPOE adoption except through their effect on hospital-physician integration. Furthermore, I find evidence that 
Table III. Average marginal effects on the marginal probability of hospital-physician integration (the first stage) from recursive bivariate probit estimation of $\mathrm{CPOE}$ and EMR probabilities using state corporate practice of medicine laws as an instrument for employment of medical staff in 2008

\begin{tabular}{|c|c|c|}
\hline \multirow[b]{2}{*}{ Variables } & \multicolumn{2}{|c|}{ Hospital-physician integration } \\
\hline & $\partial \Phi(I) / \partial X_{\mathrm{EMR}}$ & $\partial \Phi(I) / \partial X_{\mathrm{CPOE}}$ \\
\hline \multicolumn{3}{|l|}{ Hospital characteristics } \\
\hline Member of the council of teaching hospitals & $0.019(0.055)$ & $0.021(0.053)$ \\
\hline For profit & $-0.150 * * *(0.034)$ & $-0.149 * * *(0.034)$ \\
\hline Government owned (nonfederal) & $-0.039 *(0.022)$ & $-0.036(0.023)$ \\
\hline Member of a healthcare system & $-0.0057(0.021)$ & $-0.006(0.021)$ \\
\hline Percent Medicare discharges & $0.016(0.076)$ & $0.023(0.078)$ \\
\hline Percent Medicaid discharges & $-0.082(0.093)$ & $-0.097(0.093)$ \\
\hline \multicolumn{3}{|l|}{ Total admissions (1000) splines } \\
\hline$<1.34$ & & $-0.066 * *(0.028)$ \\
\hline$>1.34$ & & $0.0062 * * *(0.0015)$ \\
\hline$<0.43$ & $-0.24 * *(0.11)$ & \\
\hline $0.43-2.23$ & $-0.027 *(0.015)$ & \\
\hline $2.23-8.63$ & $0.0078 *(0.0043)$ & \\
\hline$>8.63$ & $0.0062 * * *(0.0019)$ & \\
\hline \multicolumn{3}{|l|}{ Geographic and market characteristics } \\
\hline Metropolitan or division CBSA & $-0.022(0.025)$ & $-0.019(0.023)$ \\
\hline Herfindahl Hirschman Index (rescaled by 1000 ) by HRR & $0.0018(0.013)$ & $0.002(0.013)$ \\
\hline Median household income in county (in $\$ 10,000$ ) & $-0.0133(0.0091)$ & $-0.0142(0.0092)$ \\
\hline Medicare managed care penetration in county & $-0.11(0.31)$ & $-0.05(0.11)$ \\
\hline \multicolumn{3}{|l|}{ Instrumental variable } \\
\hline Hospital bound by laws prohibiting physician employment & $-0.241 * * *(0.048)$ & $-0.243 * * *(0.047)$ \\
\hline Chi-square test of strength of instrument & 23.67 & 24.44 \\
\hline$P$ value from chi-square test & 0.000 & 0.000 \\
\hline$N$ & 3493 & 3493 \\
\hline
\end{tabular}

Standard errors calculated by the delta method are reported in parentheses. Estimates allow for correlation in the error terms within states. HRR, hospital referral region.

*Statistically significant at the $10 \%$ level.

** Statistically significant at the $5 \%$ level.

$* * *$ Statistically significant at the $1 \%$ level.

employment of physicians is endogenous with respect to hospital health IT use via a Wald test of the hypothesis that rho $=0$ in both health IT bivariate probit regressions (Table IV). This test indicates that there is substantial correlation between hospital health IT use and employment of physicians after observed factors have been accounted for. Thus, the coefficient estimate for integration in a single equation probit model will be inconsistent, and the use of an instrumental variables strategy is warranted.

\subsection{Robustness}

I tested the effect of integration on other hospital administrative IT applications for which, a priori, we would not expect a relationship with hospital-physician integration. In particular, if aligning physicians with the implementation of hospital health IT and improving communication of patient data between hospitals and physician practices are reasons why greater health IT adoption is attributable to physician employment, then there should be no relationship between employment of physicians and other IT applications that do not share these properties. I estimated the effect of integration on the probability that hospitals use administrative IT applications, including business intelligence applications, financial modeling software, and financial data warehousing systems. All of these applications are intended to provide data analysis on firm performance to hospital administrative decision makers. Both the probit results (Table V) and the bivariate probit results (Table VI) indicate no significant relationship between hospital-physician integration and these applications. 
Table IV. Average marginal effects on probability of health IT use from recursive bivariate probit estimation of CPOE and EMR probabilities using state corporate practice of medicine laws as an instrument for employment of medical staff in 2008

\begin{tabular}{|c|c|c|}
\hline & EMR & $\mathrm{CPOE}$ \\
\hline Variables & $\frac{\partial \Phi(T)}{\partial X}$ & $\frac{\partial \Phi(T)}{\partial X}$ \\
\hline \multicolumn{3}{|l|}{ Endogenous variable } \\
\hline Integrated salary model & $0.391 * * *(0.030)$ & $0.241 * * *(0.053)$ \\
\hline \multicolumn{3}{|l|}{ Hospital characteristics } \\
\hline Member of the council of teaching hospitals & $0.053 *(0.032)$ & $0.093 * * *(0.031)$ \\
\hline For profit & $-0.188 * * *(0.039)$ & $-0.019(0.033)$ \\
\hline Government owned (nonfederal) & $-0.025(0.022)$ & $0.0050(0.022)$ \\
\hline Member of a healthcare system & $0.034 * *(0.017)$ & $0.028(0.016)$ \\
\hline Percent Medicare discharges & $-0.053(0.079)$ & $-0.156^{* *}(0.066)$ \\
\hline Percent Medicaid discharges & $-0.015(0.10)$ & $-0.08(0.12)$ \\
\hline \multicolumn{3}{|l|}{ Total admissions (1000) splines } \\
\hline$<1.34$ & & $0.107 * * *(0.027)$ \\
\hline$>1.34$ & & $0.0022 * *(0.0011)$ \\
\hline$<0.43$ & $0.35 * *(0.16)$ & \\
\hline $0.43-2.23$ & $0.100 * * *(0.016)$ & \\
\hline $2.23-8.63$ & $0.0060(0.0038)$ & \\
\hline$>8.63$ & $-0.0022 *(0.0013)$ & \\
\hline \multicolumn{3}{|l|}{ Geographic and market characteristics } \\
\hline Metropolitan or division CBSA & $0.049 * * *(0.018)$ & $0.074 * * *(0.015)$ \\
\hline Herfindahl Hirschman Index (rescaled by 1000) by HRR & $-0.0014(0.0073)$ & $-0.001(0.010)$ \\
\hline Median household income in county (in $\$ 10,000$ ) & $0.0102(0.0075)$ & $0.0212 * * *(0.0076)$ \\
\hline Medicare managed care penetration in county & $0.048(0.065)$ & $0.136 * *(0.064)$ \\
\hline \multicolumn{3}{|l|}{ Tests } \\
\hline Chi-square test of instrument strength & 23.67 & 24.44 \\
\hline rho & $-0.70(0.09)$ & $-0.52(0.12)$ \\
\hline$P$ value from test of rho $=0$ & 0.0000 & 0.0003 \\
\hline$N$ & 3493 & 3493 \\
\hline
\end{tabular}

Standard errors calculated by the delta method are reported in parentheses. Estimates allow for correlation in the error terms within states. HRR, hospital referral region.

* Statistically significant at the $10 \%$ level.

** Statistically significant at the $5 \%$ level.

*** Statistically significant at the $1 \%$ level.

The null results of this falsification exercise provide some reassurance that results from the main health IT analysis constitute evidence in favor of the hypothesized relationship between physician employment and health IT.

A critical assumption for the identification of hospital-physician integration's effect on health IT adoption is that CPM laws only affect health IT adoption through physician employment by hospitals. I examine the robustness of the findings to this assumption by testing the bivariate probit models without any covariates. If association between the instrument and the unobserved variables is similar to the association between the instrument and the observed variables, then obtaining similar results without any covariates suggests the main findings are not biased by unobserved factors. In fact, I find almost no change in the effect of hospital-physician integration (columns 4 and 5 of Table VII) when all covariates are excluded (although, unsurprisingly, the estimates with covariates are more precise). Although this is reassuring, the possibility always remains that unobserved cultural and institutional factors may influence both the preservation of CPM laws and adoption of health IT, thus biasing the IV estimates. Therefore, I conducted several additional robustness tests.

Because the identification strategy depends on cross-sectional variation in state CPM regulations, I am unable to estimate models with state fixed effects. Alternatively, I estimated separate models that include indicators for state electronic discovery laws and privacy protection laws in place during 2008 as covariates. 
Table V. Average marginal effects from naive probit estimation of nonclinical IT applications as a function of hospital characteristics in 2008

\begin{tabular}{|c|c|c|c|}
\hline Variables & $\frac{\text { Business intelligence }}{\frac{\partial \Phi(T)}{\partial X}}$ & $\frac{\text { Financial modeling }}{\frac{\partial \Phi(T)}{\partial X}}$ & $\begin{array}{c}\text { Data warehousing } \\
\frac{\partial \Phi(T)}{\partial X} \\
\end{array}$ \\
\hline \multicolumn{4}{|l|}{ Endogenous variable } \\
\hline Integrated salary model & $-0.020(0.020)$ & $0.0062(0.016)$ & $-0.015(0.016)$ \\
\hline \multicolumn{4}{|l|}{ Hospital characteristics } \\
\hline Member of the council of teaching hospitals & $-0.031(0.032)$ & $-0.029(0.036)$ & $0.017(0.031)$ \\
\hline For profit & $0.076 * *(0.038)$ & $0.015(0.041)$ & $-0.063(0.053)$ \\
\hline Government owned (nonfederal) & $-0.056^{*}(0.032)$ & $-0.041(0.027)$ & $-0.056 * *(0.026)$ \\
\hline Member of a healthcare system & $0.088 * * *(0.025)$ & $0.086 * * *(0.024)$ & $0.080 * * *(0.024)$ \\
\hline Percent Medicare discharges & $-0.091(0.095)$ & $-0.124(0.089)$ & $-0.165^{*}(0.094)$ \\
\hline Percent Medicaid discharges & $-0.01(0.12)$ & $0.00(0.11)$ & $-0.05(0.14)$ \\
\hline \multicolumn{4}{|l|}{ Total admissions (1000) splines } \\
\hline$<0.43$ & $0.68 * * *(0.14)$ & $0.34 * *(0.16)$ & $0.22(0.17)$ \\
\hline $0.43-12.8$ & $0.0115 * * *(0.0030)$ & $0.0117 * * *(0.0032)$ & $0.0068 * * *(0.0025)$ \\
\hline $12.8-19$ & $-0.0108 * *(0.0052)$ & $-0.0039(0.0057)$ & $0.0013(0.0056)$ \\
\hline$>19$ & $0.0037 * * *(0.0012)$ & 0.0009 (0.0017) & $0.0013(0.0016)$ \\
\hline \multicolumn{4}{|l|}{ Geographic and market characteristics } \\
\hline Metropolitan or Division CBSA & $0.058 * * *(0.017)$ & $0.058 * *(0.026)$ & $0.094 * * *(0.015)$ \\
\hline Herfindahl Hirschman Index (rescaled by 1000) by HRR & $-0.011(0.011)$ & $-0.006(0.012)$ & $0.002(0.011)$ \\
\hline Median household income in county (in $\$ 10,000$ ) & $-0.0018(0.0098)$ & $0.0076(0.0084)$ & $-0.0099(0.0068)$ \\
\hline Medicare managed care penetration in county & $0.141 *(0.076)$ & $0.077(0.083)$ & $0.006(0.065)$ \\
\hline$N$ & 3493 & 3493 & 3493 \\
\hline
\end{tabular}

Standard errors calculated by the delta method are reported in parentheses. Estimates allow for correlation in the hospital error terms within states. HRR, hospital referral region.

*Statistically significant at the $10 \%$ level.

$* *$ Statistically significant at the $5 \%$ level.

$* * *$ Statistically significant at the $1 \%$ level.

Miller and Tucker $(2009,2011 \mathrm{a})$ have demonstrated that these two types of laws have significant effects on hospital adoption of EMR. Estimations that control for these other state regulations (in columns 6 and 7 of Table VII) show slight increases in the effect of integration with no changes in statistical significance.

Furthermore, I estimated a "placebo" version of the reduced form equation among only hospitals that do not face CPM restrictions. Thirteen percent of hospitals that do not face CPM restrictions are located in CPM enforcing states (Table I). Although the marginal effects are negative for both EMR and CPOE, they are not significantly so (last two columns of Table VII). The results of these tests provide some reassurance that CPM laws are not correlated with unobserved variables within CPM enforcing states that may be driving the main findings.

I also tested the IV model using an alternative instrument-the number of unaffiliated hospitals in the same market that employ physicians. With the alternative instrument, all analyses produce results nearly identical to the main findings (results are available from the author upon request).

\section{DISCUSSION}

This study examines the relationship between hospital employment of physicians and hospital use of health IT applications. Although a probit estimation of this relationship finds no significant effect of physician employment on the probability that hospitals use health IT, an instrumental variables analysis reveals a significant positive relationship between the two hospital strategies. These results suggest that unobserved factors, such as local costs of running independent physician practices and costs of IT adoption, influence hospitals' actions for both types of acquisitions. Measurement error in the integration variable may also 
Table VI. Average marginal effects on probability of nonclinical IT applications from recursive bivariate probit estimation using state corporate practice of medicine laws as an instrument for employment of medical staff in 2008

\begin{tabular}{|c|c|c|c|}
\hline & Business intelligence & Financial modeling & Data warehousing \\
\hline Dependent variables & $\frac{\partial \Phi(T)}{\partial X}$ & $\frac{\partial \Phi(T)}{\partial X}$ & $\frac{\partial \Phi(T)}{\partial X}$ \\
\hline \multicolumn{4}{|l|}{ Endogenous variable } \\
\hline Integrated salary model & $0.04(0.10)$ & $0.17(0.15)$ & $0.06(0.11)$ \\
\hline \multicolumn{4}{|l|}{ Hospital characteristics } \\
\hline Member of the council of teaching hospitals & $-0.035(0.036)$ & $-0.038(0.041)$ & $0.011(0.032)$ \\
\hline For profit & $0.085 *(0.046)$ & $0.043(0.049)$ & $-0.051(0.053)$ \\
\hline Government owned (nonfederal) & $-0.053(0.033)$ & $-0.032(0.030)$ & $-0.052 *(0.027)$ \\
\hline Member of a healthcare system & $0.089 * * *(0.025)$ & $0.084 * * *(0.022)$ & $0.080 * * *(0.024)$ \\
\hline Percent Medicare discharges & $-0.094(0.095)$ & $-0.135(0.085)$ & $-0.168 *(0.095)$ \\
\hline Percent Medicaid discharges & $0.00(0.12)$ & $0.012(0.11)$ & $-0.04(0.14)$ \\
\hline \multicolumn{4}{|l|}{ Total admissions (1000) splines } \\
\hline$<0.43$ & $0.70 * * *(0.15)$ & $0.37 * *(0.16)$ & $0.24(0.17)$ \\
\hline $0.43-12.8$ & $0.0113 * * *(0.0030)$ & $0.0107 * * *(0.0031)$ & $0.0066 * *(0.0026)$ \\
\hline $12.8-19$ & $-0.0115 * *(0.0054)$ & $-0.0059(0.0063)$ & $0.0003(0.0064)$ \\
\hline$>19$ & $0.0034 * * *(0.0013)$ & $-0.0001(0.0018)$ & $0.0008(0.0016)$ \\
\hline \multicolumn{4}{|l|}{ Geographic and market characteristics } \\
\hline Metropolitan or division CBSA & $0.060 * * *(0.018)$ & $0.065 * * *(0.025)$ & $0.097 * * *(0.016)$ \\
\hline Herfindahl Hirschman Index (rescaled by 1000) by HRR & $-0.013(0.012)$ & $0.0060(0.0061)$ & $0.001(0.012)$ \\
\hline Median household income in county (in $\$ 10,000$ ) & $-0.0012(0.0098)$ & $0.0091(0.0082)$ & $-0.0090(0.0072)$ \\
\hline Medicare managed care penetration in county & $0.145^{* *}(0.073)$ & $0.086(0.078)$ & $0.011(0.066)$ \\
\hline \multicolumn{4}{|l|}{ Tests } \\
\hline Chi-square test of instrument strength & 23.77 & 22.82 & 25.00 \\
\hline rho & $-0.04(0.20)$ & $-0.33(0.30)$ & $-0.12(0.23)$ \\
\hline$P$ value from test of rho $=0$ & 0.84 & 0.32 & 0.62 \\
\hline$N$ & 3493 & 3493 & 3493 \\
\hline
\end{tabular}

Standard errors calculated by the delta method are reported in parentheses. Estimates allow for correlation in the error terms within states. HRR, hospital referral region.

*Statistically significant at the $10 \%$ level.

$* *$ Statistically significant at the $5 \%$ level.

**** Statistically significant at the $1 \%$ level.

contribute to a bias toward zero (as it always does when present) in the single equation estimates. Fortunately, instrumental variables, uncorrelated with the measurement error, still produce consistent estimates in this circumstance (Angrist and Krueger, 2001). Moreover, the findings provide evidence in favor of the hypothesis of a complementary relationship between integration and health IT and suggest that hospitals with employed physicians may perceive greater net benefit from use of health IT compared with hospitals without employed physicians. This supports the transaction cost interpretation of vertical integration in that integration confers greater adaptability to the organization by lowering costs of coordinating with physicians to implement new enterprise-wide technology. Further research is needed to understand more precisely how hospital employment of physicians interacts with health IT to affect quality, outcomes, and costs of care.

A limitation regarding the generalizability of the IV results in this study should be noted. The effect of physician employment on hospital health IT adoption is identified using variation in state laws that prohibit hospitals from employing physicians. Therefore, we can only interpret the estimated impact of integration on IT adoption as the average effect among those hospitals that are bound by the laws but would have otherwise chosen to employ physicians rather than as the average effect of physician employment among all hospitals nationwide. This is the local average treatment effect interpretation of an instrumental variables analysis (Angrist and Pischke, 2009).

Although incentive payments to hospitals, such as those through the Medicare and Medicaid Meaningful Use programs, may reduce some monetary costs faced by hospitals in acquiring the technology, other organizational costs may still inhibit its effective implementation by providers. Inability to capture some benefits of 


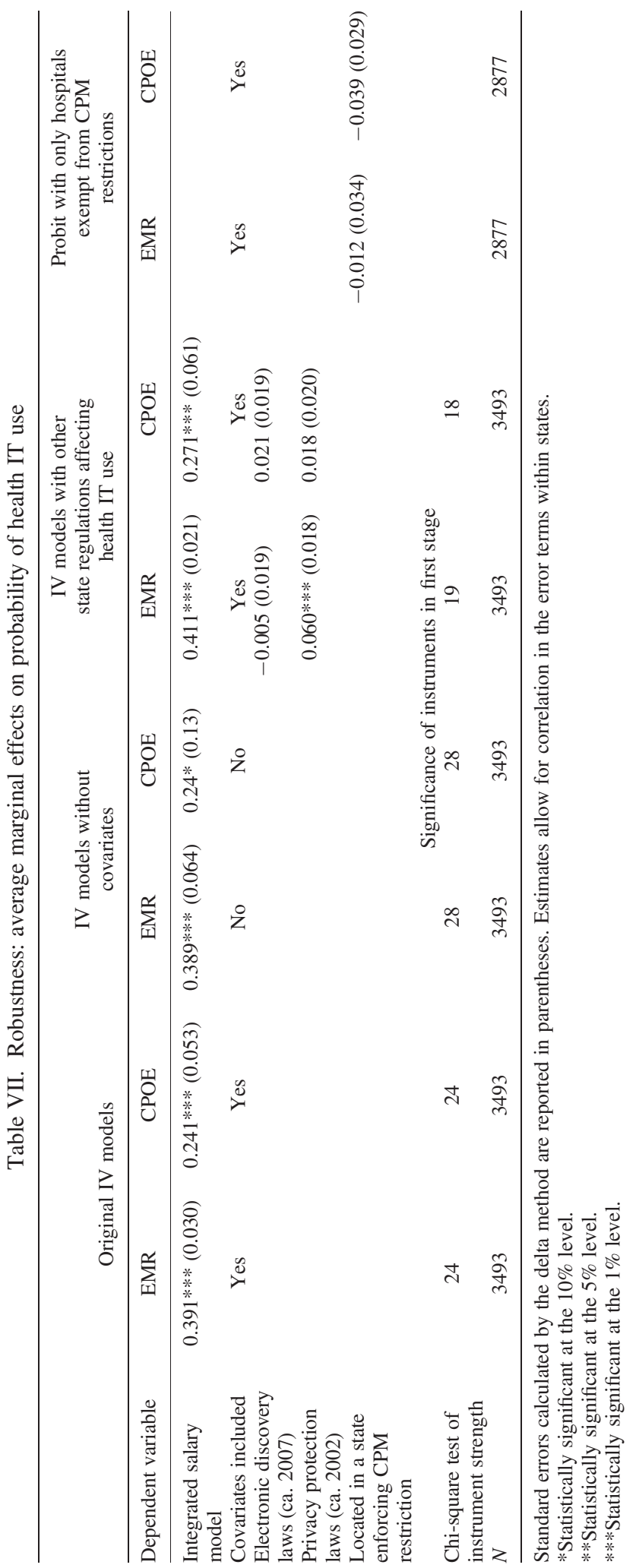


IT, such as easier exchange of patient data among providers in an integrated health system, may reduce the technology's value to hospitals that do not employ any of their physician staff. Also, provider resistance to accompanying changes in work practices may continue to slow implementation-at least in the near term until generational turnover in the medical workforce produces more cohorts of physicians primarily trained in health IT-enabled environments. CPOE in particular has been noted for engendering strong resistance (Poon et al., 2004). Some concerns on the part of providers regarding reduced productivity and new forms of error may be warranted as the work of Koppel et al. (2005) suggests. Regardless of risks associated with this particular technology, hospitals that employ their physicians may more easily coordinate with their medical staff to implement innovations that require substantial organizational change.

Lower rates of adoption among nonintegrated hospitals may also indicate a lower return from the public subsidies being given to these hospitals, thus calling into question the wisdom of subsidizing IT adoption by such hospitals. Alternatively, health IT in nonintegrated settings may still produce some value, but such hospitals may require greater incentives to support its adoption. Further research is needed to identify more precisely the relative value of the technology in integrated and nonintegrated settings. Also, from a social welfare perspective, if health IT improves quality of care (some compelling evidence for this has been produced by Miller and Tucker, 2011b, who found lower rates of neonatal mortality attributable to EMR adoption), hospital-physician integration may enhance its ability to do so. These benefits must, however, be weighed against possible costs to society if hospital-physician integration also confers greater bargaining power with payers or leads to induced demand for profitable but unnecessary medical services. Finally, the findings of this study indicate that continued enforcement of the corporate practice of medicine restrictions on hospital employment of physicians in some states inhibit hospital adoption of health IT.

\section{CONFLICT OF INTERESTS}

The author declares no conflict of interest.

\section{ACKNOWLEDGEMENTS}

Jack Albers provided excellent research assistance regarding corporate practice of medicine laws. I am also grateful to Richard Hirth, Jeff McCullough, Kai Zheng, Scott Masten, Edward Norton, and two anonymous reviewers for helpful comments and suggestions. I thank the HIMSS Foundation for providing data. This work was supported by a dissertation research grant from the Rackham Graduate School and funding from the STIET doctoral training program at the University of Michigan.

\section{REFERENCES}

Angrist JD, Krueger AB. 2001. Instrumental Variables and the Search for Identification: From Supply and Demand to Natural Experiments. The Journal of Economic Perspectives 15: 69-85.

Angrist JD, Pischke JRS. 2009. Mostly harmless econometrics: an empiricist's companion. Princeton University Press: Princeton.

Baker GP, Hubbard TN. 2004. Contractibility and Asset Ownership: On-Board Computers and Governance in U. S. Trucking. Quarterly Journal of Economics 119: 1443-1479.

Bhattacharya J, Goldman D, Mccaffrey D. 2006. Estimating probit models with self-selected treatments. Statistics in Medicine 25: 389-413.

Blumenthal D, Tavenner M. 2010. The "Meaningful Use" Regulation for Electronic Health Records. The New England Journal of Medicine 363: 501-504.

Brynjolfsson E, Malone TW, Gurbaxani V, Kambil A. 1994. Does Information Technology Lead to Smaller Firms? Management Science 40: 1628-1644. 
Burns LR, Muller RW. 2008. Hospital-physician collaboration: landscape of economic integration and impact on clinical integration. The Milbank Quarterly 86: 375-434.

Casalino LP, November EA, Berenson RA, Pham HH. 2008. Hospital-physician relations: two tracks and the decline of the voluntary medical staff model. Health Affairs 27: 1305-1314.

Cebul RD, Rebitzer JB, Taylor LJ, Votruba ME. 2008. Organizational Fragmentation and Care Quality in the U.S. Healthcare System. Journal of Economic Perspectives 22: 93-113.

Cuellar AE, Gertler PJ. 2006. Strategic integration of hospitals and physicians. Journal of Health Economics 25: 1-28.

Cutler DM, Feldman NE, Horwitz JR. 2005. U.S. adoption of computerized physician order entry systems. Health Affairs 24: $1654-1663$.

Dartmouth Medical S. 1998. The Dartmouth atlas of health care 1998. American Hospital Publishing: Chicago, Ill.

Draper DA, Berenson RA, November EA. 2009. A Tighter Bond: California Hospitals Seek Stronger Ties with Physicians. California Health Care Almanac. California HealthCare Foundation: Oakland, CA.

Gaynor M. 2011. Health Industry Consolidation. Ways and Means Health Subcommittee. Government Printing Office: Washington, D.C.

Grossman JM, Cohen G. 2008. Despite regulatory changes, hospitals cautious in helping physicians purchase electronic medical records. Issue Brief (Center for Studying Health System Change) 123: 1-4.

Harris JE. 1977. The Internal Organization of Hospitals: Some Economic Implications. Bell Journal of Economics 8: 467-482.

Hillestad R, Bigelow J, Bower A, Girosi F, Meili R, Scoville R, Taylor R. 2005. Can electronic medical record systems transform health care? Potential health benefits, savings, and costs. Health Affairs 24: 1103-1117.

Hitt LM. 1999. Information Technology and Firm Boundaries: Evidence from Panel Data. Information Systems Research 10: $134-149$.

I.O.M. 2001. Crossing the Quality Chasm: A New Health System for The 21st Century. National Academy Press: Washington, D.C.

Kazley AS, Ozcan YA. 2007. Organizational and environmental determinants of hospital EMR adoption: a national study. Journal of Medical Systems 31: 375-384.

Kim A. 2007. The Corporate Practice of Medicine Doctrine. California Research Bureau: Sacramento, CA.

Koppel R, Metlay JP, Cohen A, Abaluck B, Localio AR, Kimmel SE, Strom BL. 2005. Role of computerized physician order entry systems in facilitating medication errors. Journal of the American Medical Association 293: 1197-1203.

Masten SE. 1988. A Legal Basis for the Firm. Journal of Law, Economics, \& Organization 4: 181-198.

Mccullough JS. 2008. The adoption of hospital information systems. Health Economics 17: 649-664.

Mccullough JS, Snir EM. 2010. Monitoring technology and firm boundaries: physician-hospital integration and technology utilization. Journal of Health Economics 29: 457-467.

Menard C. 2005. A new institutional approach to organization. In Handbook of New Institutional Economics, Menard C, Shirley MM, Springerlink (eds). Springer: Boston, MA.

Miller AR, Tucker C. 2009. Privacy Protection and Technology Diffusion: The Case of Electronic Medical Records. Management Science 55: 1077-1093.

Miller AR, Tucker C. 2011a. Electronic Discovery and the Adoption of Information Technology. SSRN eLibrary.

Miller AR, Tucker CE. 2011b. Can Health Care Information Technology Save Babies? Journal of Political Economy 119: 289-324.

O'Malley AS, Bond AM, Berenson RA. 2011. Rising hospital employment of physicians: better quality, higher costs? Issue Brief (Center for Studying Health System Change) 136: 1-4.

Poon EG, Blumenthal D, Jaggi T, Honour MM, Bates DW, Kaushal R. 2004. Overcoming barriers to adopting and implementing computerized physician order entry systems in U.S. hospitals. Health Aff (Millwood) 23: 184-190.

Williamson OE. 1975. Markets and hierarchies, analysis and antitrust implications: a study in the economics of internal organization. Free Press: New York.

Yessian MR, Kvaal MB, Hereford RW. 1991. State Prohibitions on Hospital Employment of Physicians. Department of Health and Human Services, Office of Inspector General: Washington, DC. 